\title{
Correction to: Statistical analysis of NRCS curve number (NRCS-CN) in arid basins based on historical data
}

\author{
Mohammed M. Farran ${ }^{1} \cdot$ Amro M. Elfeki $^{1}$
}

Published online: 10 January 2020

(C) Saudi Society for Geosciences 2020

Correction to: Arabian Journal of Geosciences (2020) 13:31 https://doi.org/10.1007/s12517-019-4993-9

The original version of this paper was published with error. Some symbols in equations of Figure 3 went missing. Given in this article is the correct figure.

The original article has been corrected.

The online version of the original article can be found at https://oi.org/ 10.1007/s12517-019-4993-9

\section{Mohammed M. Farran}

mohamadalfaran@yahoo.com

1 Department of Hydrology and Water Resources Management, Faculty of Meteorology, Environment and Arid Land Agriculture, King Abdulaziz University, Jeddah, Saudi Arabia 
Fig. 3 Flowchart illustrates the estimation of $\mathrm{CN}$ from rainfall and runoff data
Rainfall Depth

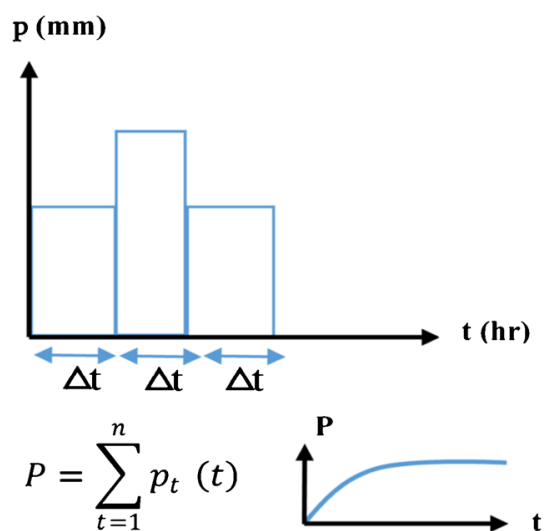

Runoff Volume

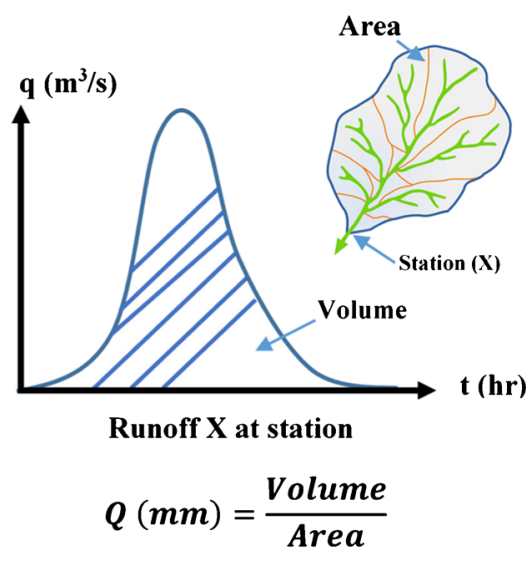

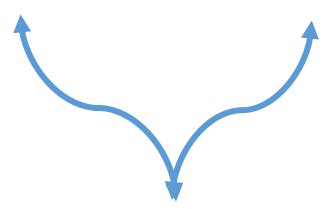

$$
\begin{gathered}
S=f(P, Q, \lambda) \\
S=\frac{P}{\lambda}+\frac{(1-\lambda) Q-\sqrt{(1-\lambda)^{2} Q^{2}+4 \lambda P Q}}{2 \lambda^{2}} \\
C N=100\left(\frac{254}{S+254}\right)
\end{gathered}
$$

Publisher's note Springer Nature remains neutral with regard to jurisdictional claims in published maps and institutional affiliations. 